\title{
Existence of nonoscillatory solutions of higher-order neutral differential equations with positive and negative coefficients
}

\author{
Youjun Liu', Huanhuan Zhao' and Jurang Yan²
}

"Correspondence: lyj9791@126.com 'College of Mathematics and Computer Sciences, Shanxi Datong University, Datong, Shanxi 037009, P.R. China

Full list of author information is available at the end of the article

\begin{abstract}
In this paper we consider the existence of nonoscillatory solutions of higher-order neutral differential equations with distributed coefficients and delays. We use the Banach contraction principle to obtain new sufficient condition for the existence of nonoscillatory solutions.
\end{abstract}

Keywords: nonlinear; neutral; distributed delays; nonoscillatory solutions; Banach contraction principle

\section{Introduction}

In this paper, we consider the higher-order nonlinear neutral differential equation with distributed coefficients

$$
\left[\Phi\left[r(t) x(t)+\int_{a}^{b} p(t, \theta) x(t-\theta) d \theta\right]\right]^{(n)}+q_{1}(t) g_{1}(x(t-\tau))-q_{2}(t) g_{2}(x(t-\sigma))=h(t) .
$$

Throughout this paper, the following conditions are assumed to hold.

(1) $n \geq 1$ is a positive integer, $r \in C\left(\left[t_{0}, \infty\right), R^{+}\right), 0<a<b, \tau>0, \sigma>0$;

(2) $p \in C\left(\left[t_{0}, \infty\right) \times[a, b], R\right), q_{1} \in C\left(\left[t_{0}, \infty\right), R^{+}\right), q_{2} \in C\left(\left[t_{0}, \infty\right), R^{+}\right), h \in C\left(\left[t_{0}, \infty\right), R\right)$;

(3) $\Phi(u)$ is a continuously increasing real function with respect to $u$ defined on $R$, and $\Phi^{-1}(u)$ satisfies the local Lipschitz condition;

(4) $g_{i} \in C(R, R), g_{i}(u)$ satisfy the local Lipschitz condition and $u g_{i}(u)>0, i=1$, 2, for $u \neq 0$.

Recently there have been a lot of activities concerning the existence of nonoscillatory solutions for neutral differential equations with positive and negative coefficients. In 2002, Zhou and Zhang [1] studied the higher-order linear neutral delay differential equation

$$
\frac{d^{n}}{d t^{n}}[x(t)+c x(t-\tau)]+(-1)^{n+1}[P(t) x(t-\sigma)-Q(t) x(t-\delta)]=0
$$

In 2005, the existence of nonoscillatory solutions of first-order linear neutral delay differential equations of the form

$$
\frac{d}{d t}[x(t)+P(t) x(t-\tau)]+Q_{1}(t) x\left(t-\sigma_{1}\right)-Q_{2}(t) x\left(t-\sigma_{2}\right)=0
$$

(c) 2016 Liu et al. This article is distributed under the terms of the Creative Commons Attribution 4.0 International License (http://creativecommons.org/licenses/by/4.0/), which permits unrestricted use, distribution, and reproduction in any medium, provided you give appropriate credit to the original author(s) and the source, provide a link to the Creative Commons license, and indicate if changes were made. 
was investigated by Zhang et al. [2] and, in the same year, Yu and Wang [3] studied nonoscillatory solutions of second-order nonlinear neutral differential equations of the form

$$
\left[r(t)[x(t)+P(t) x(t-\tau)]^{\prime}\right]^{\prime}+Q_{1}(t) f\left(x\left(t-\sigma_{1}\right)\right)-Q_{2}(t) g\left(x\left(t-\sigma_{2}\right)\right)=0 .
$$

In 2010, Candan and Dahiya [4] studied nonoscillatory solutions of first-order and secondorder nonlinear neutral differential equations with positive and negative coefficients,

$$
\frac{d^{k}}{d t^{k}}[x(t)+P(t) x(t-\tau)]+\int_{a}^{b} q_{1}(t, \xi) x(t-\xi) d \xi-\int_{c}^{d} q_{2}(t, \mu) x(t-\mu) d \mu=0, \quad k=1,2 .
$$

In 2012, Candan [5] studied the higher-order nonlinear differential equation

$$
\left[r(t)[x(t)+P(t) x(t-\tau)]^{(n-1)}\right]^{\prime}+(-1)^{n}\left[Q_{1}(t) g_{1}\left(x\left(t-\sigma_{1}\right)\right)-Q_{2}(t) g_{2}(x(t-\mu))-f(t)\right]=0 .
$$

As can be seen from the development process of the above equations, the delays of the neutral part in the discussed differential equations were all constant delays, and the main thought in the employed verification method also was kept the same in which the coefficient neutral part in the neutral were all discussed in four cases, that is, $(-\infty,-1),(-1,0)$, $(0,1),(1,+\infty)$, and then they were verified by constructing the corresponding operator. However, studies of the case for distributed deviating arguments are rather rare. In 2013, Candan [6] studied a first-order neutral differential equation with distributed deviating arguments,

$$
\left[\left[x(t)-\int_{a}^{b} p_{2}(t, \xi) x(t-\xi) d \xi\right]^{\gamma}\right]^{\prime}+\int_{c}^{d} Q_{2}(t, \xi) G(x(t-\xi)) d \xi=0,
$$

where $\gamma$ is a ratio of odd positive integers, however, the discussion only covered the condition for the coefficient being $0<\int_{a}^{b} p_{2}(t, \xi) d \xi<1$, while without the other three conditions, which might be caused by the difficulty in establishing feasible operator. In view of the above, here, in this paper, the difficulty of an operator establishment was settled and sufficiency conditions for the existence of nonoscillatory solutions of differential equation with coefficient of $\int_{a}^{b} p_{2}(t, \xi) d \xi$ in the four cases were obtained. Thus, this paper may have theoretical value as well as practical application value. For related work, we refer the reader to [7-17].

As usual, a solution of equation (1) is said to be oscillatory if it has arbitrarily large zeros. Otherwise the solution is said to be nonoscillatory.

A solution of equation (1) is a continuous function $x(t)$ defined on $\left[t_{1}-\mu, \infty\right)$, for some $t_{1}>t_{0}$, such that $\Phi\left[r(t) x(t)+\int_{a}^{b} p(t, \theta) x(t-\theta) d \theta\right]$ is $n$ times continuously differentiable and equation (1) holds for all $n \geq 1$. Here, $\mu=\max \{b, \tau, \sigma\}$.

Let $L_{i}, i=1,2$. denote the Lipschitz constants of the functions $g_{i}, i=1,2$ on the set $A$, $K$ denote the Lipschitz constants of functions $\Phi^{-1}(u)$, respectively, and $L=\max \left\{L_{1}, L_{2}\right\}$, $\beta_{i}=\max _{x \in A} g_{i}(x), i=1,2$.

Let $\Omega$ be the set of all continuous and bounded functions on $\left[t_{0}, \infty\right)$ and the norm be $\|x(t)\|=\sup _{t_{0} \leq t<+\infty} x(t)$. 


\section{The main results}

Theorem Assume that

$$
\begin{aligned}
& \int_{t}^{\infty} s^{n-1} q_{i}(s) d s<\infty, \quad i=1,2, \\
& \int_{t}^{\infty} s^{n-1} h(s) d s<\infty,
\end{aligned}
$$

and $\int_{a}^{b} p(t, \theta) d \theta$ satisfies one of the following conditions:
(a) $0 \leq \int_{a}^{b} p(t, \theta) d \theta<1$,
(b) $1<\int_{a}^{b} p(t, \theta) d \theta<+\infty$,
(c) $-1<\int_{a}^{b} p(t, \theta) d \theta \leq 0$,
(d) $-\infty<\int_{a}^{b} p(t, \theta) d \theta<-1$.

Then equation (1) has a bounded nonoscillatory solution.

Proof Case (a): $0 \leq \int_{a}^{b} p(t, \theta) d \theta \leq p_{1}<1$. Set $A=\left\{x \in \Lambda, M_{1} \leq x(t) \leq M_{2}, t \geq t_{0}\right\}$, where $M_{1}, M_{2}$ are two positive constants such that $p_{1} M_{2}+\frac{M_{1}}{p_{1}}<\alpha<M_{2}, 1 \leq r(t) \leq \frac{1}{p_{1}}$. From (3), one can choose a $t_{1} \geq t_{0}+b$, and a sufficiently large $t \geq t_{1}$ such that

$$
\begin{aligned}
& \int_{t}^{\infty} \frac{(s-t)^{n-1}}{(n-1) !}\left[\beta_{1} q_{1}(s)+|h(s)|\right] d s \leq \Phi\left(M_{2}\right)-\Phi(\alpha), \\
& \int_{t}^{\infty} \frac{(s-t)^{n-1}}{(n-1) !}\left[\beta_{2} q_{2}(s)+|h(s)|\right] d s \leq \Phi(\alpha)-\Phi\left(p_{1} M_{2}+\frac{M_{1}}{p_{1}}\right), \\
& \int_{t}^{\infty} \frac{(s-t)^{n-1}}{(n-1) !}\left[q_{1}(s)+q_{2}(s)\right] d s \leq \frac{1-p_{1}}{K L},
\end{aligned}
$$

and define an operator $T$ on $A$ as follows:

$$
(T x)(t)=\left\{\begin{array}{rlrl}
\frac{1}{r(t)}\left\{-\int_{a}^{b} p(t, \theta) x(t-\theta) d \theta\right. & \\
& +\Phi^{-1}\left[\Phi(\alpha)+\int_{t}^{\infty} \frac{(s-t)^{n-1}}{(n-1) !}\left[q_{1}(s) g_{1}(x(s-\tau))\right.\right. & \\
\left.\left.\left.-q_{2}(s) g_{2}(x(s-\sigma))-h(s)\right] d s\right]\right\}, & & t \geq t_{1}, \\
(T x)\left(t_{1}\right), & t_{0} \leq t \leq t_{1} .
\end{array}\right.
$$

It is easy to see that $T$ is continuous, for $t \geq t_{1}, x \in A$. By using (4), we have

$$
\begin{aligned}
(T x)(t) & \leq \frac{1}{r(t)}\left\{\Phi^{-1}\left[\Phi(\alpha)+\int_{t}^{\infty} \frac{(s-t)^{n-1}}{(n-1) !}\left[q_{1}(s) g_{1}(x(s-\tau))-h(s)\right] d s\right]\right\} \\
& \leq \Phi^{-1}\left[\Phi(\alpha)+\int_{t}^{\infty} \frac{(s-t)^{n-1}}{(n-1) !}\left(\beta_{1} q_{1}(s)+|h(s)|\right) d s\right] \\
& \leq M_{2}
\end{aligned}
$$


and taking (5) into account, we have

$$
\begin{aligned}
(T x)(t) \geq & \frac{1}{r(t)}\left\{-\int_{a}^{b} p(t, \theta) x(t-\theta) d \theta\right. \\
& \left.-\Phi^{-1}\left[\Phi(\alpha)+\int_{t}^{\infty} \frac{(s-t)^{n-1}}{(n-1) !}\left[q_{2}(s) g_{2}(x(s-\sigma))-h(s)\right] d s\right]\right\} \\
\geq & p_{1}\left\{-p_{1} M_{2}-\Phi^{-1}\left[\Phi(\alpha)+\int_{t}^{\infty} \frac{(s-t)^{n-1}}{(n-1) !}\left(\beta_{2} q_{2}(s)+|h(s)|\right) d s\right]\right\} \\
\geq & M_{1} .
\end{aligned}
$$

These show that $T A \subset A$. Since $A$ is a bounded, closed, convex subset of $\Lambda$, in order to apply the contraction principle we have to show that $T$ is a contraction mapping on $A$. For $\forall x_{1}, x_{2} \in A$, and $t \geq t_{1}$,

$$
\begin{aligned}
& \left|\left(T x_{1}\right)(t)-\left(T x_{2}\right)(t)\right| \\
& \leq \frac{1}{r(t)}\left\{\int_{a}^{b} p(t, \theta)\left|x_{1}(t-\theta)-x_{2}(t-\theta)\right| d \theta\right. \\
& \quad+\Phi^{-1}\left[\Phi(\alpha)+\int_{t}^{\infty} \frac{(s-t)^{n-1}}{(n-1) !}\left|q_{1}(s) g_{1}\left(x_{1}(s-\tau)\right)-q_{2}(s) g_{2}\left(x_{1}(s-\sigma)\right)-h(s)\right| d s\right] \\
& \quad-\Phi^{-1}\left[\Phi(\alpha)+\int_{t}^{\infty} \frac{(s-t)^{n-1}}{(n-1) !} \mid q_{1}(s) g_{1}\left(x_{2}(s-\tau)\right)\right. \\
& \left.\left.\quad-q_{2}(s) g_{2}\left(x_{2}(s-\sigma)\right)-h(s) \mid d s\right]\right\} \\
& \leq \frac{1}{r(t)}\left\{p_{1}\left|x_{1}-x_{2}\right|+K \int_{t}^{\infty} \frac{(s-t)^{n-1}}{(n-1) !}\left[q_{1}(s)\left|g_{1}\left(x_{1}(s-\tau)\right)-g_{1}\left(x_{2}(s-\tau)\right)\right|\right.\right. \\
& \left.\left.\quad+q_{2}(s)\left|g_{2}\left(x_{1}(s-\sigma)\right)-g_{2}\left(x_{2}(s-\sigma)\right)\right|\right] d s\right\} .
\end{aligned}
$$

Using (6),

$$
\begin{aligned}
\left|\left(T x_{1}\right)(t)-\left(T x_{2}\right)(t)\right| & \leq\left|x_{1}-x_{2}\right|\left(p_{1}+K L \int_{t}^{\infty} \frac{(s-t)^{n-1}}{(n-1) !}\left[q_{1}(s)+q_{2}(s)\right] d s\right) \\
& <\left|x_{1}-x_{2}\right| .
\end{aligned}
$$

This implies with the sup norm that

$$
\left\|T x_{1}-T x_{2}\right\|<\left\|x_{1}-x_{2}\right\|
$$

which shows that $T$ is a contraction mapping on $A$ and therefore there exists a unique solution, obviously a bounded positive solution of (1) $x \in A$, such that $T x=x$.

Case (b): $1<p_{3} \leq \int_{a}^{b} p(t, \theta) d \theta \leq p_{2}<2 p_{3}<+\infty$. Set $A=\left\{x \in \Lambda, M_{3} \leq x(t) \leq M_{4}, t \geq t_{0}\right\}$, where $M_{3}, M_{4}$ are two positive constants such that $p_{2} M_{4}+2 p_{2} M_{3}<\alpha<2 p_{3} M_{4}, 2 p_{3} \leq$ $r(t) \leq 2 p_{2}$. From (3), one can choose a $t_{1} \geq t_{0}+b$, and a sufficiently large $t \geq t_{1}$ such that

$$
\int_{t}^{\infty} \frac{(s-t)^{n-1}}{(n-1) !}\left[\beta_{1} q_{1}(s)+|h(s)|\right] d s \leq \Phi\left(2 p_{3} M_{4}\right)-\Phi(\alpha)
$$




$$
\begin{aligned}
& \int_{t}^{\infty} \frac{(s-t)^{n-1}}{(n-1) !}\left[\beta_{2} q_{2}(s)+|h(s)|\right] d s \leq \Phi(\alpha)-\Phi\left(p_{2} M_{4}-2 p_{2} M_{3}\right), \\
& \int_{t}^{\infty} \frac{(s-t)^{n-1}}{(n-1) !}\left[q_{1}(s)+q_{2}(s)\right] d s \leq \frac{2 p_{3}-p_{2}}{K L}
\end{aligned}
$$

and we define an operator $T$ on $A$ as follows:

$$
(T x)(t)=\left\{\begin{aligned}
\frac{1}{r(t)}\left\{-\int_{a}^{b} p(t, \theta) x(t-\theta) d \theta\right. & \\
\quad+\Phi^{-1}\left[\Phi(\alpha)+\int_{t}^{\infty} \frac{(s-t)^{n-1}}{(n-1) !}\left[q_{1}(s) g_{1}(x(s-\tau))\right.\right. & \\
\left.\left.\left.-q_{2}(s) g_{2}(x(s-\sigma))-h(s)\right] d s\right]\right\}, & t \geq t_{1}, \\
(T x)\left(t_{1}\right), & t_{0} \leq t \leq t_{1} .
\end{aligned}\right.
$$

It is easy to see that $T$ is continuous, for $t \geq t_{1}, x \in A$. By using (7), we have

$$
\begin{aligned}
(T x)(t) & \leq \frac{1}{r(t)}\left\{\Phi^{-1}\left[\Phi(\alpha)+\int_{t}^{\infty} \frac{(s-t)^{n-1}}{(n-1) !}\left[q_{1}(s) g_{1}(x(s-\tau))-h(s)\right] d s\right]\right\} \\
& \leq \frac{1}{2 p_{3}}\left\{\Phi^{-1}\left[\Phi(\alpha)+\int_{t}^{\infty} \frac{(s-t)^{n-1}}{(n-1) !}\left[\beta_{1} q_{1}(s)+|h(s)|\right] d s\right]\right\} \\
& \leq M_{4},
\end{aligned}
$$

and taking (8) into account, we have

$$
\begin{aligned}
(T x)(t) \geq & \frac{1}{r(t)}\left\{-\int_{a}^{b} p(t, \theta) x(t-\theta) d \theta\right. \\
& \left.+\Phi^{-1}\left[\Phi(\alpha)+\int_{t}^{\infty} \frac{(s-t)^{n-1}}{(n-1) !}\left[q_{2}(s) g_{2}(x(s-\sigma))-h(s)\right] d s\right]\right\} \\
\geq & \frac{1}{2 p_{2}}\left\{-p_{2} M_{4}-\Phi^{-1}\left[\Phi(\alpha)+\int_{t}^{\infty} \frac{(s-t)^{n-1}}{(n-1) !}\left(\beta_{2} q_{2}(s)+|h(s)|\right) d s\right]\right\} \\
\geq & M_{3} .
\end{aligned}
$$

These show that $T A \subset A$. Since $A$ is a bounded, closed, convex subset of $\Lambda$, in order to apply the contraction principle, we have to show that $T$ is a contraction mapping on $A$. For $\forall x_{1}, x_{2} \in A$, and $t \geq t_{1}$,

$$
\begin{aligned}
& \left|\left(T x_{1}\right)(t)-\left(T x_{2}\right)(t)\right| \\
& \leq \frac{1}{r(t)}\left\{\int_{a}^{b} p(t, \theta)\left|x_{1}(t-\theta)-x_{2}(t-\theta)\right| d \theta\right. \\
& \quad+\Phi^{-1}\left[\Phi(\alpha)+\int_{t}^{\infty} \frac{(s-t)^{n-1}}{(n-1) !}\left|q_{1}(s) g_{1}\left(x_{1}(s-\tau)\right)-q_{2}(s) g_{2}\left(x_{1}(s-\sigma)\right)-h(s)\right| d s\right] \\
& \left.\quad-\Phi^{-1}\left[\Phi(\alpha)+\int_{t}^{\infty} \frac{(s-t)^{n-1}}{(n-1) !}\left|q_{1}(s) g_{1}\left(x_{2}(s-\tau)\right)-q_{2}(s) g_{2}\left(x_{2}(s-\sigma)\right)-h(s)\right| d s\right]\right\} \\
& \leq \\
& \quad \frac{1}{r(t)}\left\{p_{2}\left\|x_{1}-x_{2}\right\|+K \int_{t}^{\infty} \frac{(s-t)^{n-1}}{(n-1) !}\left[q_{1}(s)\left|g_{1}\left(x_{1}(s-\tau)\right)-g_{1}\left(x_{2}(s-\tau)\right)\right|\right.\right. \\
& \left.\left.\quad+q_{2}(s)\left|g_{2}\left(x_{1}(s-\sigma)\right)-g_{2}\left(x_{2}(s-\sigma)\right)\right|\right] d s\right\},
\end{aligned}
$$


or using (9),

$$
\begin{aligned}
\left|\left(T x_{1}\right)(t)-\left(T x_{2}\right)(t)\right| & \leq\left|x_{1}-x_{2}\right| \frac{1}{2 p_{3}}\left\{p_{2}+K L \int_{t}^{\infty} \frac{(s-t)^{n-1}}{(n-1) !}\left[q_{1}(s)+q_{2}(s)\right] d s\right\} \\
& <\left|x_{1}-x_{2}\right| .
\end{aligned}
$$

This implies with the sup norm that

$$
\left\|T x_{1}-T x_{2}\right\|<\left\|x_{1}-x_{2}\right\|
$$

which shows that $T$ is a contraction mapping on $A$ and therefore there exists a unique solution, obviously a bounded positive solution of (1) $x \in A$, such that $T x=x$.

Case (c): $-1<p_{4} \leq \int_{a}^{b} p(t, \theta) d \theta \leq 0$. Set $A=\left\{x \in \Lambda, M_{5} \leq x(t) \leq M_{6}, t \geq t_{0}\right\}$, where $M_{5}$, $M_{6}$ are two positive constants such that $\frac{M_{5}}{-p_{4}}<\alpha<\left(1+p_{4}\right) M_{6}, 1 \leq r(t) \leq \frac{1}{-p_{4}}$. From (3), one can choose a $t_{1} \geq t_{0}+b$, and a sufficiently large $t \geq t_{1}$ such that

$$
\begin{aligned}
& \int_{t}^{\infty} \frac{(s-t)^{n-1}}{(n-1) !}\left[\beta_{1} q_{1}(s)+|h(s)|\right] d s \leq \Phi\left(\left(1+p_{4}\right) M_{6}\right)-\Phi(\alpha), \\
& \int_{t}^{\infty} \frac{(s-t)^{n-1}}{(n-1) !}\left[\beta_{2} q_{2}(s)+|h(s)|\right] d s \leq \Phi(\alpha)-\Phi\left(-\frac{M_{5}}{p_{4}}\right), \\
& \int_{t}^{\infty} \frac{(s-t)^{n-1}}{(n-1) !}\left[q_{1}(s)+q_{2}(s)\right] d s \leq \frac{1+p_{4}}{K L} .
\end{aligned}
$$

The remaining part of the proof of (c) is similar to the proof of part (a), therefore it is omitted.

Case (d): $-\infty<2 p_{5}<p_{6} \leq \int_{a}^{b} p(t, \theta) d \theta \leq p_{5}<-1$. Set $A=\left\{x \in \Lambda, M_{7} \leq x(t) \leq M_{8}, t \geq\right.$ $\left.t_{0}\right\}$, where $M_{7}, M_{8}$ are two positive constants such that $-2 p_{6} M_{7}<\alpha<\left(-2 p_{5}+p_{6}\right) M_{8}$, $-2 p_{5}<r(t)<-2 p_{6}$. From (3), one can choose a $t_{1} \geq t_{0}+b$, and a sufficiently large $t \geq t_{1}$ such that

$$
\begin{aligned}
& \int_{t}^{\infty} \frac{(s-t)^{n-1}}{(n-1) !}\left[\beta_{1} q_{1}(s) d \tau+|h(s)|\right] d s \leq \Phi\left(-2 p_{5} M_{8}+p_{6} M_{8}\right)-\Phi(\alpha) \\
& \int_{t}^{\infty} \frac{(s-t)^{n-1}}{(n-1) !}\left[\beta_{2} q_{2}(s)+|h(s)|\right] d s \leq \Phi(\alpha)-\Phi\left(-2 p_{6} M_{7}\right) \\
& \int_{t}^{\infty} \frac{(s-t)^{n-1}}{(n-1) !}\left[q_{1}(s)+q_{2}(s) d\right] d s \leq \frac{p_{6}-2 p_{5}}{K L}
\end{aligned}
$$

The remaining part of the proof of (d) is similar to the proof of part (b), therefore it is omitted. The proof is complete.

\section{Example}

Example Consider a high-order neutral differential equation with distributed deviating arguments

$$
\begin{aligned}
& {\left[\left(\frac{3}{2+\sin t} x(t)+\int_{\frac{\pi}{2}}^{\pi} e^{-t} x(t-\theta) d \theta\right)^{3}\right]^{\prime \prime}+36 e^{-t} x\left(t-\frac{\pi}{2}\right)-36 \pi e^{-2 t} x(t-\pi)} \\
& \quad=e^{-3 t}\left(15 \cos ^{3} t-30 \sin ^{3} t+63 \pi \sin ^{2} t-18 \pi \cos ^{2} t\right.
\end{aligned}
$$




$$
\begin{aligned}
& \left.+\frac{1}{2} \sin 2 t\left(15 \cos t-27 \sin ^{2} t+33 \pi\right)+6 \pi^{2}(\cos t-7 \sin t)+9 \pi^{3}\right) \\
& +18 e^{-2 t}(4 \pi \cos t+\cos 2 t-\sin 2 t-4 \pi)-18 e^{-t}(2 \sin t-\pi-4)
\end{aligned}
$$

Here, $n=2, r(t)=\frac{3}{2+\sin t}, P(t, \theta)=e^{-t}, q_{1}(t)=36 e^{-t}, q_{2}(t)=36 \pi e^{-2 t}, \Phi(u)=u^{3}, g_{1}(u)=$ $g_{2}(u)=u, a=\frac{\pi}{2}, b=\pi, \tau=\frac{\pi}{2}, \sigma=\pi .1<r(t)=\frac{3}{2+\sin t}<3, \int_{\frac{\pi}{2}}^{\pi} e^{-t} d \theta=\frac{\pi}{2} e^{-t}<1, \int_{t_{0}}^{\infty} s e^{-s} d s<$ $\infty, \int_{t_{0}}^{\infty} s e^{-2 s} d s<\infty, \int_{t_{0}}^{\infty} e^{-3 s} \mid 15 \cos ^{3} s-30 \sin ^{3} s+63 \pi \sin ^{2} s-18 \pi \cos ^{2} s+\frac{1}{2} \sin 2 s(15 \cos s-$ $\left.27 \sin ^{2} s+33 \pi\right)+6 \pi^{2}(\cos s-7 \sin s)+9 \pi^{3}\left|+18 e^{-2 s}\right| 4 \pi \cos s+\cos 2 s-\sin 2 s-4 \pi \mid-$ $18 e^{-s}|2 \sin s-\pi-4| d s<\infty$.

Then it is easy to see that all the conditions of Theorem are satisfied. In fact, $x(t)=$ $2+\sin t$ is a nonoscillatory solution of equation (10).

\section{Results and discussion}

We obtained a new sufficiency condition for the existence of nonoscillatory solutions of higher-order neutral differential equations with distributed coefficients and delays.

\section{Conclusions}

In this paper we use the Banach contraction principle to obtain a sufficiency condition for the existence of nonoscillatory solutions of a differential equation with coefficient of $\int_{a}^{b} p_{2}(t, \xi) d \xi$ in the four cases.

\section{Competing interests}

The authors declare that they have no competing interests.

\section{Authors' contributions}

$Y L$ conceived of the study and helped to draft the manuscript. $\mathrm{HZ}$ undertook the numerical calculation and a revision of the English. JY established the feasible operator and participated in its design. All authors read and approved the final manuscript.

\section{Author details}

${ }^{1}$ College of Mathematics and Computer Sciences, Shanxi Datong University, Datong, Shanxi 037009, P.R. China. ${ }^{2}$ School of Mathematical Sciences, Shanxi University, Taiyuan, Shanxi 030006, P.R. China.

\section{Acknowledgements}

The authors thank the referees for useful suggestions, which helped to improve the presentation. We appreciate the selfless help from professor Jianwen Zhang in this manuscript. This research is supported by Scientific Research Project Shanxi Datong University (No. 2011 K3) and Scientific Research Start-up Funding of Doctor of Shanxi Datong University (2015-B-07).

Received: 9 May 2016 Accepted: 13 September 2016 Published online: 22 September 2016

\section{References}

1. Zhou, Y, Zhang, BG: Existence of nonoscillatory solutions of higher-order neutral differential equations with positive and negative coefficients. Appl. Math. Lett. 15, 867-874 (2002)

2. Zhang, W, Feng, W, Yan, J, Song, J: Existence of nonoscillatory solutions of first-order linear neutral delay differential equations. Comput. Math. Appl. 49, 1021-1027 (2005)

3. Yu, Y, Wang, H: Nonoscillatory solution of second-order nonlinear neutral delay equations. J. Math. Anal. Appl. 311 , 445-456 (2005)

4. Candan, T, Dahiya, RS: Existence of nonoscillatory solutions of first and second order neutral differential equations with distributed deviating arguments. J. Franklin Inst. 347, 1309-1316 (2010)

5. Candan, T: The existence of nonoscillatory solutions of higher order nonlinear neutral differential equations. Appl. Math. Lett. 25, 412-416 (2012)

6. Candan, T: Existence of nonoscillatory solutions of first-order nonlinear neutral differential equations. Appl. Math. Lett. 26, 1182-1186 (2013)

7. Liu, Y, Zhang, J, Yan, J: Existence of nonoscillatory solutions of higher order neutral differential equations with distributed deviating arguments. Acta Math. Appl. Sin. 38(2), 235-243 (2015) (in Chinese)

8. Öcalan, Ö: Existence of positive solutions for a neutral differential equation with positive and negative coefficients. Appl. Math. Lett. 22, 84-90 (2009)

9. Candan, T: Existence of nonoscillatory solutions for system of higher order neutral differential equations. Math. Comput. Model. 57, 375-381 (2013) 
10. Liu, Y, Zhang, J, Yan, J: Existence of nonoscillatory solutions for system of higher-order neutral differential equations with distributed deviating arguments. Discrete Dyn. Nat. Soc. 2013, Article ID 391973 (2013)

11. Kulenović, MRS, Hadžiomerspahić, S: Existence of nonoscillatory solutions second-order linear neutral delay equations. J. Math. Anal. Appl. 228, 436-448 (1998)

12. Öcalan, Ö: Oscillation of neutral equations with positive and negative coefficients. J. Math. Anal. Appl. 331, 644-654 (2007)

13. Li, T, Han, Z, Sun, S, Yang, D: Existence of nonoscillatory solutions to second-order neutral delay dynamic equations on time scales. Adv. Differ. Equ. 2009, Article ID 562329 (2009)

14. Li, T, Baculíková, B, Džurina, J: Oscillatory behavior of second-order nonlinear neutral differential equations with distributed deviating arguments. Bound. Value Probl. 2014, Article ID 68 (2014)

15. Li, T, Rogovchenko, YV: Oscillation criteria for even-order neutral differential equations. Appl. Math. Lett. 61, 35-41 (2016)

16. Jiang, C, Jiang, Y, Li, T: Asymptotic behavior of third-order differential equations with nonpositive neutral coefficients and distributed deviating arguments. Adv. Differ. Equ. 2016, Article ID 105 (2016)

17. Györi, I, Ladas, G: Oscillation Theory of Delay Differential Equations with Applications. Clarendon, Oxford (1991)

Submit your manuscript to a SpringerOpen ${ }^{\circ}$ journal and benefit from:

- Convenient online submission

Rigorous peer review

- Immediate publication on acceptance

- Open access: articles freely available online

- High visibility within the field

- Retaining the copyright to your article 